\title{
'Home Field Advantage' Works in Business as well as Baseball
}

\author{
Olav Sorenson (UCLA Anderson School of Management) \\ Michael S. Dahl (Aalborg University)
}

\section{KEYWORDS: Social Media \& Networks, Entrepreneurship, Organization, Leadership, Alliance Management, Distribution Relationships, Startups, Team Development, Research Insight.}

Entrepreneurs with great ideas often feel they must pull up stakes and move to a region that is known as a hub for their specific industry. But research that we published in 2012 suggests that they shouldn't be so hasty to pack their bags: that the home field advantage can work in business as well as in baseball.

We discovered that entrepreneurs who start their companies in places where they have deep roots earn higher profits and have lower failure rates than those who found them in unfamiliar locations. The results, published in 2012, come from analyzing more than 13,000 Danish startups, in industries such as hospitality, retail, professional services, construction and IT services. [1].

Our research found that companies founded by people who have been "embedded" in the region for longer periods of time performed better than newcomers. For example, a company headed by someone who had lived in a region for five years earned nearly $\$ 6,400$ more in annual profits and had a roughly $6 \%$ percent lower "failure" rate than a company headed by a recent arrival to the region, where failure means the venture closing or the founder returning to being employed by someone else.

Although our study had been focused on the potential benefits of starting a company locally, we also analyzed the effect of other variables on a startup's survival and profits: industry experience; demographics such as the founder's age, education, and marital status; and financial resources such as the founder's household wealth and parents' wealth.

Some of our other findings include:
- Homegrown entrepreneurs enjoy the greatest success in less populated regions, which presumably have more tightly-woven social fabrics.

- Entrepreneurs with prior experience in the industry in which they start their firms, or in closely related ones, also earn more and have lower failure rates.

- Success in terms of the survival of the business peaks for entrepreneurs around age 42. Men and married entrepreneurs also have lower failure rates than women and single entrepreneurs.

- Parents' wealth had as large of a positive effect on a venture's success as the entrepreneur's own household wealth.

Why do homegrown entrepreneurs perform better? We speculate that two factors play a role: First, they know the territory; they understand which products and services their regions need and can spot opportunities. Second, they have connections. Their well-established networks of contacts likely give them better access to financing and to potential employees and business partners. Local lenders and investors, for example, may trust those with deep roots in the area more than recent arrivals.

The length of time spent living in a region can rival or even surpass industry experience in the edge it gives to entrepreneurs. With time in the region, the issue is not human capital, which entrepreneurs can carry with them to other locations, but social capital, which they often cannot.

We believe that our research holds lessons not just for entrepreneurs but also for companies and individuals 
looking to do business in an unfamiliar region. Other research, for example, has found that foreign companies face many obstacles-import duties, transportation costs, and suspicion from the targeted region-when they want to expand outside their home countries.

Our results demonstrate that this disadvantage of not being from a region extends to the individual level, that it can occur even in the absence of legal, linguistic, or cultural barriers, and that it exists at much finer-grained geographic scales than the crossing of national boundaries.

The best-case scenario: know both the industry and the territory. As we write in our paper, "Rational entrepreneurs would enter the industries in which they have employment experience and locate their businesses in the regions in which they have lived."

\section{Editor's Commentary}

Entrepreneurs often struggle with the decision of where to start their company. Many argue that entrepreneurs are best served by moving to geographic areas known to foster startups for specific industries-such as Silicon Valley in the case of computer software.

Dahl and Sorenson's study provides important insight into the effects of location that sheds light on the commonly held belief that entrepreneurs must locate their companies in specific regions if they wish to be successful. If nothing else, their work makes the case that entrepreneurs who pull up stakes to start a company risk losing the benefits of their wellestablished networks back home.

An important issue for further research is to consider how business accelerators might alter the ability for entrepreneurs to be successful in starting companies in regions outside where they have strong local ties. An attribute of business accelerators is that they leverage regional resources to benefit companies that participate in their program-even if a company is a newcomer to the region [2]. While our scientific understanding of the effectiveness of business accelerators is still being developed, early observations suggest that accelerators might help entrepreneurs overcome some of the issues of geography uncovered by Dahl and Sorenson's important work. -- Jon Eckhardt, EIX Senior Editor for Research, University of Wisconsin-Madison

\section{References}

1. Dahl MS, Sorenson O. Home Sweet Home: Entrepreneurs' Location Choices and the Performance of Their Ventures (http://pubsonline.informs.org/doi/abs/10.1287/ mnsc.1110.1476) . Manage Sci. pubsonline.informs.org; 2012;58: 1059-1071.

2. Hallen BL, Bingham CB, Cohen S. Do Accelerators Accelerate? A Study of Venture Accelerators as a Path to Success? Academy of Management Proceedings. Academy of Management; 2014: 12955. 